\title{
Surgical Removal of Numerous Foreign Body Gastric Bezoar: A Case Report
}

\author{
Mohamed Ahmed ${ }^{1}$, Saba Habis ${ }^{2}$, Ahmed Mahmoud ${ }^{1}$, Rasha Saeed ${ }^{1}$, Mohamed Elkahly ${ }^{1}$ \\ 1. Surgery, Riverside Community Hospital, Riverside, USA 2. Internal Medicine, Riverside Community \\ Hospital, Riverside, USA
}

$\square$ Corresponding author: Mohamed Ahmed, maamsmd@yahoo.com

Disclosures can be found in Additional Information at the end of the article

\section{Abstract}

A 53-year-old mentally retarded male was brought to our emergency room after vomiting a plastic glove. Computed tomography revealed marked gastric distention containing large amount of residual food debris. Endoscopic retrieval was unsuccessful. Surgical removal of the foreign bodies was done. The patient did well and was discharged from the hospital.

Categories: Psychiatry, Gastroenterology, General Surgery

Keywords: gastric outlet obstruction, bezoar, mental retardation

\section{Introduction}

Gastric bezoars are foreign bodies in the stomach that increase in size due to accumulation of nonabsorbable food or fibers [1]. It is defined as "any of various calculi found chiefly in the gastrointestinal organs and formerly believed to possess magical properties from Arabic bāzahr" [2]. The clinical picture ranges from abdominal pain, nausea, vomiting, early satiety and weight loss, to bleeding ulcer, intestinal obstruction and perforation [3].

\section{Case Presentation}

A 53-year-old mentally retarded male was brought to our emergency room after vomiting a plastic glove. The patient had two weeks history of intermittent nausea and vomiting. Computed tomography of the abdomen showed a non-enhancing mixed density intraluminal gastric mass (Figure 1). 


\section{Cureus}

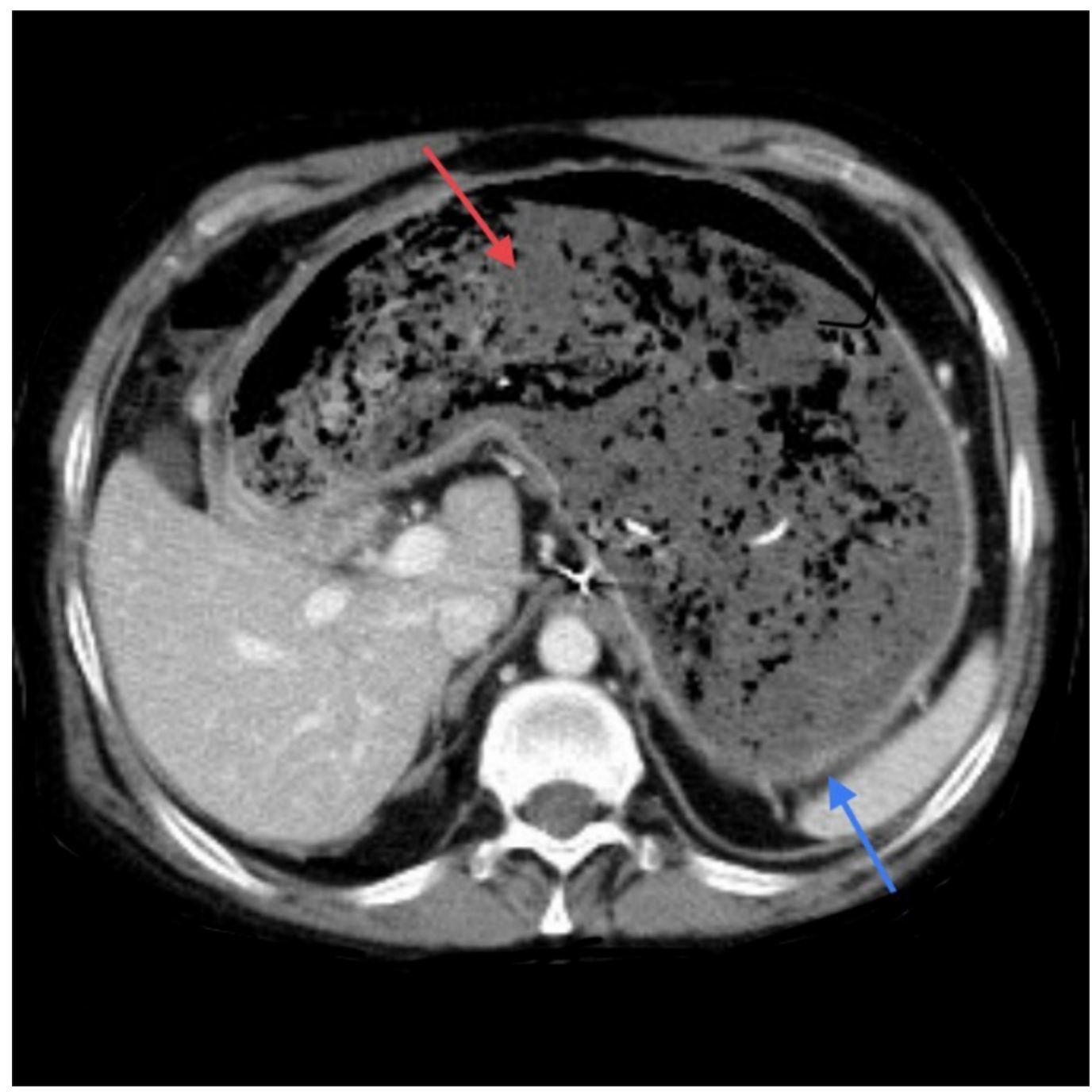

FIGURE 1: Computed tomography (CT) scan abdomen.

Stomach (blue arrow). None enhancing mass (red arrow).

An endoscopy done to confirm the diagnosis and retrieve the foreign bodies was not successful. The patient was taken to the operating room and an upper midline incision was done (multiple previous abdominal surgeries). Gastrotomy and foreign body bezoars removal was performed (Figure 2). 


\section{Cureus}

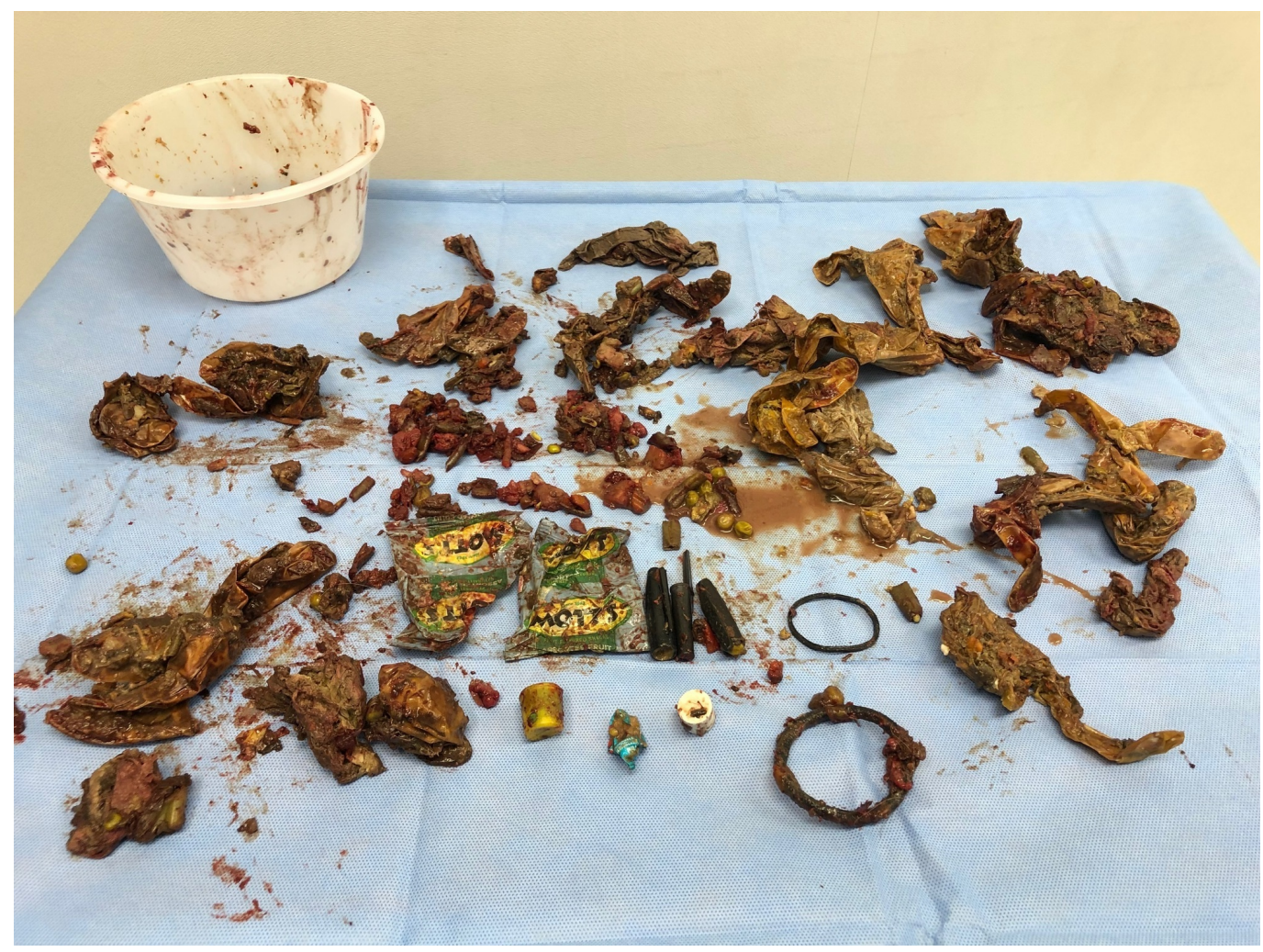

FIGURE 2: Stomach content.

Variety of foreign bodies retrieved.

The patient did well and was discharged from the hospital.

\section{Discussion}

More than $90 \%$ of bezoars cases are found in children and young female with pica, psychiatric disorders, or mental retardation [4], but rarely a severe psychiatric disorder is seen [5]. The clinical picture ranges from abdominal pain, nausea, vomiting, early satiety and weight loss, to bleeding ulcer, intestinal obstruction and perforation. Anemia and hypoalbuminemia associated with chronic gastritis usually go unnoticed until the case is brought to light by the onset of more severe complications such as hemorrhage, enteric or pancreatic or biliary obstruction [6]. Diagnostic modalities include abdominal ultrasound (US), computed tomography (CT) scan and upper endoscopy. CT scan has a higher accuracy rate than US [7]. Treatment of bezoars includes observation, dissolution, fragmentation, laparotomy or laparoscopic gastrotomy for removal. Gastroscopic fragmentation, nasogastric lavage or suction, and enzymatic therapy with cellulose and papain have been tried [8]. In our case, the use of endoscopy was not successful and surgical retrieval was the best option.

\section{Conclusions}

Bezoars are a potentially serious problem. Treatment includes gastric lavage, dissolution, endoscopic retrieval and surgery. It is prudent to prevent future occurrences via dietary counseling, avoidance of certain medications, and correction of underlying motility disorders if present. After successful management, psychiatric evaluation should be considered and the patient and/or his care giver should be educated to prevent recurrence. 


\section{Additional Information \\ Disclosures}

Human subjects: Consent was obtained by all participants in this study. Conflicts of interest: In compliance with the ICMJE uniform disclosure form, all authors declare the following:

Payment/services info: All authors have declared that no financial support was received from any organization for the submitted work. Financial relationships: All authors have declared that they have no financial relationships at present or within the previous three years with any organizations that might have an interest in the submitted work. Other relationships: All authors have declared that there are no other relationships or activities that could appear to have influenced the submitted work.

\section{References}

1. Sharma D, Srivastava M, Babu R, Anand R, Rohtagi A, Thomas S: Laparoscopic treatment of gastric bezoar. JSLS. 2010, 14:263-267. 10.4293/108680810X12785289144566

2. Merriam-Webster. (2019). Accessed: February 6, 2019: https://www.merriamwebster.com/dictionary/bezoar.

3. Kadian R, Rose J, Mann N: Gastric bezoars--spontaneous resolution. Am J Gastroenterol. 1978, 70:79-82.

4. Nirasawa Y, Mori T, Ito Y, Tanaka H, Seki N, Atomi Y: Laparoscopic removal of a large gastric trichobezoar. J Pediatr Surg. 1998, 33:663-665.

5. O'Sullivan M, McGreal G, Walsh J: Trichobezoar. J R Soc Med. 2001, 94:68-70. 10.1177/014107680109400205

6. Rabie M, Arishi A, Khan A, Ageely H, Seif El-Nasr GA, Fagihi M: Rapunzel syndrome: the unsuspected culprit. World J Gastroenterol. 2008, 14:1141-1143. 10.3748/wjg.14.1141

7. Sharma K, Sharma Y, Chhetri R, Makaju RK, Chapagain S, Shrestha R: Epigastric mass in a young girl: trichobezoar. Imaging diagnosis. Nepal Med Coll J. 2006, 8:211-212.

8. Shami S, Jararaa A, Hamade A, Ammori B: Laparoscopic removal of a huge gastric trichobezoar in a patient with trichotillomania. Surg Laparosc Endosc Percutan Tech. 2007, 17:197-200. 10.1097/SLE.0b013e318058a101 